This item was submitted to Loughborough's Research Repository by the author.

Items in Figshare are protected by copyright, with all rights reserved, unless otherwise indicated.

\title{
The daily incidence of out-of-hospital cardiac arrest unexpectedly increases around New Year's Day in Japan
}

\section{PLEASE CITE THE PUBLISHED VERSION}

http://dx.doi.org/10.1016/j.resuscitation.2015.08.003

\section{PUBLISHER}

(c) Elsevier Ireland Ltd.

\section{VERSION}

AM (Accepted Manuscript)

\section{PUBLISHER STATEMENT}

This work is made available according to the conditions of the Creative Commons Attribution-NonCommercialNoDerivatives 4.0 International (CC BY-NC-ND 4.0) licence. Full details of this licence are available at: https://creativecommons.org/licenses/by-nc-nd/4.0/

\section{LICENCE}

CC BY-NC-ND 4.0

\section{REPOSITORY RECORD}

Takahashi, Kunihiko, and Hideyasu Shimadzu. 2019. "The Daily Incidence of Out-of-hospital Cardiac Arrest Unexpectedly Increases Around New Year's Day in Japan”. figshare. https://hdl.handle.net/2134/20998. 


\title{
The daily incidence of out-of-hospital cardiac arrest unexpectedly increases around New Year's Day in Japan
}

\author{
Kunihiko Takahashi ${ }^{1}$ and Hideyasu Shimadzu ${ }^{2}$
}

\begin{abstract}
Background: Over 100,000 patients are diagnosed every year as out-of-hospital cardiac arrest (OHCA) cases in Japan and their number has continued to rise for the last decade, presenting a challenge for preventive public health research as well as emergency medical care. The purpose of this study was to identify whether there are any temporal patterns in daily OHCA presentations in Japan.

Methods: Records of OHCA patients $(n=701,651)$ transported by ambulance over the course of six years (1st January 2005 to 10th March 2011) in Japan were obtained from the All-Japan Utstein registry data of cardiopulmonary arrest patients. Time periods within which the incidence of OHCA significantly increased were identified by a temporal cluster detection test using scan statistics. The risk ratios of OHCA for the detected periods were calculated and adjusted according to a Poisson regression model accounting for effects of other factors.

Results: The risk of OHCA significantly rises 1.3 to 1.6 times around New Year's Day in Japan.

Conclusions: Our analysis revealed the increased daily incidence of OHCA around every New Year's Day in Japan.
\end{abstract}

Keywords: Cardiac arrest, Out-of-hospital, Time series, Temporal clustering, New Year's Day

\footnotetext{
1 Department of Biostatistics, Nagoya University Graduate School of Medicine, Nagoya, Japan. kunihiko@med.nagoya-u.ac.jp

2 Centre for Biological Diversity and Scottish Oceans Institute, University of St Andrews, UK.
}

This is authors' version postprint of: Kunihiko Takahashi and Hideyasu Shimadzu (2015) The daily incidence of out-of-hospital cardiac arrest unexpectedly increases around New Year's Day in Japan. Resuscitation. doi: http://dx.doi.org/10.1016/j.resuscitation.2015.08.003 


\section{INTRODUCTION}

Over 100,000 patients are diagnosed every year as out-of-hospital cardiac arrest (OHCA) cases in Japan and their number continues to rise, with a $20 \%$ increase between 2005 and 2013. These cases account for $2.0 \%$ to $2.3 \%$ of emergency cases transported by ambulance, as reported by the Fire and Disaster Management Agency (FDMA) of the Ministry of Internal Affairs, Communications, Japan ${ }^{1}$. OHCA cases have become a major public health issue in Japan, a challenge facing preventive public health research as well as emergency medical care.

From a public health perspective, it is important to understand factors that can be potential hazards contributing to the incidence of OHCA. For example, the incidence of cardiac arrests is known to be related to ambient climate conditions, namely low temperatures, which consequently increase the risk of heart disease and the number of OHCA cases during winter seasons $\mathbf{s}^{2,3}$. This association concurs with official statistics reported at a Fire and Disaster Management conference on the practical applications of emergency statistics. Empana et $\mathrm{al}^{4}$ report that heat waves can also cause a significant increase in OHCA cases.

Once the event occurs, improved survival from OHCA relies on emergency medical care services and largely depends on primary access to necessary medical care such as early cardiopulmonary resuscitation, rapid defibrillation, and integrated post-cardiac arrest care ${ }^{5}$. It is a challenge for emergency medical care providers to providing care as swiftly as possible. Accordingly, several studies have investigated the extent to which the chances of resuscitation and survival vary over different conditions ${ }^{6-10}$ including the types of symptoms, treatment provided $^{11-13}$, patients' attributes ${ }^{14,15}$ and situations ${ }^{5,16-20}$. These previous studies have mostly utilized monthly observations of OHCA cases that had already occurred to investigate outcomes in relation to emergency care procedures. Despite such active research, the importance of taking pre-emptive actions for OHCA, such as predicting the occurrence patterns of OHCA over time, has been understated ${ }^{21}$. With predictions we could know a priori when the demand on emergency care facilities might increase, allowing us to improve the present emergency protocol for OHCA cases.

It is essential to obtain OHCA and weather data on a finer spatio-temporal scale and detailed background information of patients to be able to identify the daily trends in OHCA and whether there are any particular time periods within which the incidence notably increases. In this study, we examined daily ambulance records of OHCA cases in Japan to 
identify any temporal patterns in OHCA presentation, taking into account environmental factors such as low and high temperature.

\section{METHODS}

\section{Data}

Daily ambulance records of OHCA cases were obtained from the All-Japan Utstein registry data of cardiopulmonary arrest patients provided by FDMA. This was a nationwide and population-based registry system of OHCA cases available since 2005, in accordance with the Utstein guidelines ${ }^{22,23}$. Since all the records were made anonymous by FDMA, according to the informed consent guidelines in Japan ${ }^{24}$ we were exempt from obtaining informed consent from each patient to use this dataset. We set the study period from 1st January 2005 to 10th March 2011 (2,260 days), before the Great East Japan Earthquake occurred, to avoid any heterogeneity induced by the natural disaster. The 701,651 cases were separately analyzed based on sex and the etiology of cardiac arrest (Table 1, Figure 1).

The meteorology data were obtained from the Japan Meteorological Agency website $^{25}$. Since the fluctuation of temperature records showed similar patterns for the maximum, minimum, and average temperature among weather stations, apart from a consistent difference in absolute values, we used the daily average temperature observed at a Tokyo weather station in the present analysis. The minimum, 25th percentile, 50th percentile, 75th percentile, and maximum temperature values were $1.3^{\circ} \mathrm{C}, 9.0^{\circ} \mathrm{C}, 16.3^{\circ} \mathrm{C}, 22.9^{\circ} \mathrm{C}$, and $32.7^{\circ} \mathrm{C}$, respectively, throughout the study period.

\section{Detecting temporal clustering of out-of-hospital cardiac arrest cases}

To detect a time period within which the incidence of OHCA became higher than expected, we adopted a cluster detection test widely used in spatial epidemiology contexts that calculates scan statistics under a Poisson model as proposed by Kulldorff et al ${ }^{26}$. This allows us to detect temporal clusters of OHCA cases under a statistical hypothesis test setting without undertaking multiple testing. The expected number of OHCA cases, $\mu_{i}$, on day $i$, was estimated by a Poisson regression model for observed OHCA cases $D_{i}$, accommodated 2 by 2 stratification by sex (male/female) and the etiology of arrest (cardiac/non-cardiac). This model represents the null hypothesis that there was no clustering of OHCA cases during the study period. We considered five factors in the model: year $(y=2005, \ldots, 2011)$, month $(m=1,2, \ldots, 12)$, weekday $(w=1$ for Sunday; $\ldots ;=7$ for Saturday), holidays $(h=1$ for 
national holidays and the Japanese new year holiday period, 28th December through 3rd January, excluding Saturdays and Sundays or $h=0$ otherwise), and temperature $\left(t_{i}\right)$. To account for the effects of temperature, we employed a twofold linear-threshold model ${ }^{27}$ : $t_{C, i}=\max \left\{\left(\tau_{C}-t_{i}\right), 0\right\}$ and $t_{H, i}=\max \left\{\left(t_{i}-\tau_{H}\right), 0\right\}$ for temperature either below the low threshold $\tau_{C}$ (cold effects) or above the high threshold $\tau_{H}$ (heat effects). These were modeled as lag effects up to $L$ days. The model is given as (Model 1)

$$
\log \left(\mu_{i}\right)=\beta_{0}+\beta_{y}+\beta_{m}+\beta_{w}+\beta_{h}+\sum_{l=0}^{L} \beta_{T C, l} t_{C, i-l}+\sum_{l=0}^{L} \beta_{T H, l} t_{H, i-l},
$$

where $\beta_{0}, \beta_{y}, \beta_{m}, \beta_{w}, \beta_{h}, \beta_{T H, l}, \beta_{T H, l}$ are the coefficients to be estimated, but those estimates $\beta_{y}, \beta_{m}, \beta_{w}$ and $\beta_{h}$, are set to be 0 for the cases $y=2005, m=1$ (January), $w=1$ (Sunday) and $h=0$ (weekday) as constraints. The time lag $L$ was initially set to be six days. The thresholds $\left(\tau_{C}, \tau_{H}\right)$ were respectively estimated for each stratum as $21.6^{\circ} \mathrm{C}$ and $26.9^{\circ} \mathrm{C}$ for the male cardiac (MC) cases, $25.3^{\circ} \mathrm{C}$ and $25.4^{\circ} \mathrm{C}$ for the male non-cardiac (MNC) cases, $22.1^{\circ} \mathrm{C}$ and $28.3^{\circ} \mathrm{C}$ for the female cardiac (FC) cases, and $21.7^{\circ} \mathrm{C}$ and 29.7 for the female non-cardiac (FNC) cases, by maximizing the likelihood of Model 1 for each stratum.

To examine whether the incidence of OHCA cases showed any particular temporal clustering, we calculated flexible scan statistics implemented with the restricted likelihood ratio $^{28}$. This was an improved version of Kulldorff's analysis. We set two default arguments of the program: the maximum temporal length of a cluster was set to 20 days and the pre-specified significance level for a restriction was set as $\alpha_{1}=0.2$. The significance level of the test was set as $\alpha=0.05$ and its $p$-value was calculated from 999 replications of the Monte Carlo hypothesis testing.

The regression analysis was carried out using $\mathrm{R}$, version $3.1 .2^{29}$, and the cluster detection test was performed using FleXScan, version 3.1.2 ${ }^{30}$.

\section{Adjusted risk ratio for clustered periods of out-of-hospital cardiac arrest}

To quantify the increased incidence of OHCA around New Year's Day in particular, we introduced a new variable "significantly clustered period around New Year's Day" (SCP-NY) for those days around New Year's Day. The periods of clustering were identified by the temporal cluster detection test with $p<0.05$. We further examined another model below, incorporating the SCP-NY effect $\beta_{S C P}$ as 
(Model 2)

$$
\log \left(\mu_{i}\right)=\beta_{0}+\beta_{y}+\beta_{m}+\beta_{w}+\beta_{h}+\sum_{l=0}^{L} \beta_{T C, l} t_{C, i-l}+\sum_{l=0}^{L} \beta_{T H, l} t_{H, i-l}+\beta_{S C P}
$$

for day $i$. Note that $\beta_{S C P}=0$ indicating those days outside the SCP-NY. Here, the length of the time lag and the two thresholds were set to be the same as in Model 1 for each stratum. The adjusted risk ratio (RR) for the clustered period of OHCA was estimated as $\exp \left(\beta_{S C P}\right)$.

To compare the model performance between Models 1 and 2, we used Akaike's Information Criterion (AIC) ${ }^{31}$. The model with the smaller AIC value was considered to be a better model.

\section{RESULTS}

\section{Temporal clustering of out-of-hospital cardiac arrest cases}

The prediction of Model 1 highlights a notable increase in the incidence of OHCA cases observed around every New Year's Day over all the strata: MC, MNC, FC, and FNC (Figure 1). This observation concurs with the results of the cluster detection test. Table 2 lists the periods detected with $p<0.05$. For the MC group, six of the nine periods identified were in fact SCP-NY with $p=0.001$. This was common across the other strata; almost all the detected periods involved New Year's Day. Strikingly, there were no other shared periods detected among the strata, except the SCP-NY.

\section{High risk of out-of-hospital cardiac arrest around New Year's Day}

The RR was calculated for each factor considered in Model 2 (Table 3). The RRs for SCP-NY were higher than for the other factors across all the strata. The risk of OHCA increased 1.3 to 1.6 times during the SCP-NY compared with the rest of the year: 1.281 (95\% confidence interval: 1.246-1.316) (MC), 1.609 (1.551-1.670) (MNC), 1.311 (1.261-1.363) (FC), and 1.437 (1.375-1.501) (FNC). AIC calculated for Models 1 and 2 supports Model 2 as a better model, suggesting that the SCP-NY effect may have caused a significant increase in the incidence of OHCA cases (AIC: Model 1 vs. Model 2: 17495 vs. 17197, MC; 17504 vs. 16935, MNC; 16845 vs. 16674 , FC; and 16135 vs. 15891, FNC).

Our model also delineated the incidence of OHCA cases according to year, month, weekday, and holidays, showing consistent patterns over the strata. The incidence continued to increase over the last decade, with a yearly drift that increased during winter seasons as well as on Sundays and holidays (Figure 1). 
The effect of ambient temperature, low or high temperature relative to the threshold, was also associated with the daily incidence of OHCA. Those days with temperatures lower than the threshold (about $20^{\circ} \mathrm{C}$ ) tended to have a moderate increase in OHCA cases and those with temperatures slightly higher than the threshold $\left(25^{\circ} \mathrm{C}-30^{\circ} \mathrm{C}\right)$ showed significant increases in the incidence, apart from the MNC group. The estimated RRs for high temperature and its lag effects, however, were almost 1.0, although some significant coefficients were observed. We note that the re-estimated thresholds of Model 2 showed no change from those of Model 1.

\section{DISCUSSION}

We examined the daily records of OHCA cases in Japan and revealed that the incidence of OHCA significantly increased during a particular time of year, specifically around New Year's Day. Further, the adjusted RR of SCP-NY accommodating the other factors (seasons, holidays, and temperature) were 1.3 to 1.6 , which suggests that the SCP-NY may cause an increase in the incidence of OHCA. Here, we further discuss plausible reasons causing the increased incidence during the periods detected as the significantly clustered period, SCP-NY, in the context of previous research.

\section{Differences in out-of-hospital cardiac arrest cases between New Year's and other time periods}

Utilizing two models (Model 1 and 2) that differed in whether the effect of SCP-NY was considered, we examined the temporal fluctuations in OHCA incidence. The estimated parameters showed little difference between Model 1 and 2. Further, the cluster detection test based on Model 2 identified only the clusters that were not around New Year's Day that were already detected by the test based on Model 1 (data not shown). These indicate the existence of factors that were not accounted for by the present model.

We extended our investigation to look for such factors among the different attributes between the patient groups presenting with OHCA during the SCP-NY period and during the rest of the year. However, few differences were identified (Table A1 and A2 in supplementary material). We have compared the frequency of the cases in January based on patient age, time of the call, witnessed cardiac arrest (i.e. the incident was encountered by bystanders), etiology, return of spontaneous circulation, one-month survival, and regions. The regional comparison included six groups in which the 47 prefectures were merged along with their population size: 
1) Tokyo (10.3\% of the total population in Japan), 2) Kanagawa (7.0\%), 3) Osaka (6.9\%), 4) six prefectures from $4^{\text {th }}$ to $9^{\text {th }}$ : Aichi, Saitama, Chiba, Hyogo, Hokkaido, Fukuoka $\left.(28.8 \%), 5\right)$ 11 prefectures from $10^{\text {th }}$ to $20^{\text {th }}(21.3 \%)$, and 6$)$ the other 27 prefectures $(25.6 \%)$. No differences were found in each stratum between the patient groups during the SCP-NY or during other times of the year based on the factors listed above, except that witnessed cardiac arrests of the MNC and FNC groups were more common in SCP-NY. Compared to those of cardiac cases, the RRs for SCP-NY were higher in non-cardiac cases which include the consequences of cerebrovascular disease, respiratory disease, malignant tumor, external causes, and any other non-cardiac causes based on medical records; those other non-cardiac causes accounted for about $40 \%$ of the whole non-cardiac cases, including asphyxia, hanging, fall, drowning, traffic injury, drug overuse and unclassified external cases ${ }^{10}$. Excess occurrences due to suicide and traffic accidents, which are also related to the other non-cardiac causes, around New Year's Day were not reported, and only a slight increase of external causes was recognized in MNC.

Regarding the influence of other potential environmental factors, we refer to Omori et al $^{32}$, who investigated the mortality of residents aged over 65 years from 1990 to 1994 in Japan. They report that mortality was linked to respiratory and cardiovascular diseases, as well as the effects of particulate matter and other environment factors that we have not considered in the present study. They had, in fact, illustrated a trend in the number of deaths with peaks in January or February; however, these peaks presented did not coincide with ours in Figure 1.

McMichaen $^{33}$ and $\mathrm{Ng}^{34}$ reported the influence of temperature extremes on increased mortality. In our model, we considered the temperature effects as relative effects, rather than absolute effects, taking the daily average and its adjacent effects (lags) observed in Tokyo. The threshold of temperature effects were estimated by maximizing the likelihood of the model. It would also be useful to accommodate local temperature records in the model to pursue a local scale analysis that accounts for the absolute temperature effect. Our model, however, clearly demonstrated an association between low temperatures and increased incidence of OHCA cases, suggesting that our model was capable of accounting for such temperature extremes. The RRs for low temperature effects of the day (lag 0) were 1.02 to 1.07. However, considering the fact that the observed temperature during the detected SCP-NY was not extremely low, we cannot conclude at this stage that the factors discussed in 
the studies above $\mathrm{e}^{32-34}$ were the hidden factors causing the increased incidence of OHCA. These factors could be potential candidates for future studies.

\section{Temperature and holiday effects for significant clusters not around New Year's Day}

In contrast, two factors, temperature upper extremes (heat waves) and holiday effects, may contribute to the significant clustering of OHCA cases that did not occur around New Year's Day. Although the RRs for the effects of high temperature were close to 1.0, the cluster detection test suggests that heat waves may cause increased incidence of OHCA. For example, the period 22nd-27th July 2010, was detected as a period with significant clustering of OHCA cases for the MC and FNC groups and includes a record heat wave. The daily average and maximum temperature for those days (20-24 July, 2010) stayed above $30^{\circ} \mathrm{C}$ (daily averages: $30.8^{\circ} \mathrm{C}, 31.5^{\circ} \mathrm{C}, 31.4^{\circ} \mathrm{C}, 30.8^{\circ} \mathrm{C}$, and $30.8^{\circ} \mathrm{C}$; daily maximums: $34.5^{\circ} \mathrm{C}, 36.3^{\circ} \mathrm{C}, 36.1^{\circ} \mathrm{C}$, $35.7^{\circ} \mathrm{C}$ and $\left.35.8^{\circ} \mathrm{C}\right)$. However, these were slightly lower than another period, 16-17th August 2010 (daily averages: $32.2^{\circ} \mathrm{C}$ and $32.3^{\circ} \mathrm{C}$; daily maximums: $36.3^{\circ} \mathrm{C}$ and $37.2^{\circ} \mathrm{C}$ ), suggesting that the increased incidence may be related to not only high temperature itself but also its abrupt rise.

Furthermore, some major public holiday seasons in Japan, such as those around 5th May (Golden Week) and 13-15th August (Obon), were detected as periods with significant clustering of OHCA cases for some strata. Although the temperature in mid-August included a recorded heat wave in 2007, we note that the detected increased incidence of OHCA for the FNC group (9-17th August 2007) also overlapped with a common holiday period, Obon. Another detected period of significant clustering, 6-7th May 2010 for the MC and FC groups, fell between the public holidays of Golden Week and many people may have extended their holiday on those days. During long holidays, people visit their family or go on trips, exposing themselves to unusual situations and/or unfamiliar places that could present potential health hazards. It is notable that many clinics and hospitals, except holiday on-duty doctors, are closed during those holidays. This forces people to alter their routine check-up schedule and may limit access to proper medical care. This could also contribute to the increased incidence of OHCA and may increase the risks associated with underlying diseases such as hypertension and diabetes. 


\section{Limitations and future research}

In our study, we detected significant clustering of OHCA cases across all strata during the period around New Year's Day almost every year and across some strata around certain public holidays in some years. This implies that the causes of the increased incidence of OHCA in the New Year season include not only temperature and holiday effects but also confounding factors, such as social and cultural activities, which were not included in the present analyses. More detailed information regarding these factors is required for further investigation.

An update of the Utstein reporting framework has been discussed by the International Liaison Committee on Resuscitation since 2012 to $2014{ }^{35}$, and new recommendations have been reported ${ }^{36}$. New Utstein OHCA elements that will be recorded include patient demographics, comorbidities, etiology, initial presentation, and bystander response. These elements are new to the current template. The new framework also suggests that information about the location of arrest and whether bystanders are present should be provided. As pointed out by some reports ${ }^{6,17}$, more than two-thirds of OHCA cases are found at the patient's house, so the suggested additional information will allow us to undertake more detailed investigations regarding factors related to the incidence of OHCA. It will open up new opportunities to enhance our preventive epidemiological research as well as improve the present emergency protocol for OHCA in the near future.

\section{CONCLUSIONS}

The incidence of OHCA cases was unexpectedly increased and significantly clustered around New Year's Day in Japan, suggesting that extra emergency medical care may be required for those periods. Our analysis also revealed that collecting patients' information with more detailed individual attributes is essential for identifying the factors contributing to the increased incidence of OHCA during those periods; this will advance future research in preventive public health.

\section{Conflict of interest:}

All authors have no conflicts of interest to disclose.

\section{Acknowledgements}

HS acknowledges the European Research Council (project BioTIME 250189). 


\section{References}

1. Fire and Disaster Management Agency of the Ministry of Internal Affairs and Communications. White Paper on Fire and Disaster Management 2013. (in Japanese). http://www.fdma.go.jp/html/hakusho/h25/h25/index.html (accessed 1 Apr 2015).

2. Bagai A, McNally BF, Al-Khatib SM, Myers JB, Kim S, Karlsson L, Torp-Pedersen C, Wissenberg M, van Diepen S, Fosbol EL, Monk L, Abella BS, Granger CB, Jollis JG. Temporal differences in out-of-hospital cardiac arrest incidence and survival. Circulation 2013; 128: 2595-602.

3. Fukuda T, Ohashi N, Doi K, Matsubara T, Kitsuta Y, Nakajima S, Tahagi N. Impact of seasonal temperature environment on the neurologic prognosis of out-of-hospital cardiac arrest: A nationwide, population-based cohort study. Journal of Critical Care 2014; 29: 840-7. 4. Empana JP, Sauval P, Ducimetiere P,Tafflet M, Carli P, Jouven X. Increase in out-of-hospital cardiac arrest attended by the medical mobile intensive care units, but not myocardial infarction, during the 2003 heat wave in Paris, France. Critical Care Medicine 2009; 37(12): 3079-84. DOI: 10.1097/CCM.0b013e3181b0868f.

5. Hasegawa K, Hiraide A, Chang Y, Brown DFM. Accociation of prehospital advanced airway management with neurologic outcome and survival in patients with out-of-hospital cardiac arrest. JAMA 2013; 309(3): 257-66.

6. Engdahl J, Holmberg M, Karlson BW, Luepker R, Herlitz J. The epidemiology of out-of-hospital 'sudden' cardiac arrest. Resuscitation 2002; 52: 235-45.

7. Sasson C, Rogers MAM, Dahk J,Kellermann AL. Predictors of survival from out-of-hospital cardiac arrest: A systematic review and meta-analysis. Circ Cardiovasc Qual Outcomes 2010; 3: 63-81.

8. Väyrynen T, Boyd J, Sorsa M, Sorsa M, Määttä T, Kuisma M. Long-term changes in the incidence of out-of-hospital ventricular fibrillation. Resuscitation 2011; 82:825-9.

9. Nürnberger A, Sterz F, Malzed R, Warenits A, Girsa M, Stöckl M, Hlavi G, Magnet IAM, Weiser C, Zajicek A, Glück H, Grava MS, Müller V, Benold N, Hubner P, Kaff A. Out of hospital cardiac arrest in Vienna: Incidence and outcome. Resuscitation 2013; 84: 42-7. 10. Kitamura T, Kiyohara K, Sakai T, Iwami T, Nishiyama C, Kajino K, Nishiuchi T, Hayashi Y, Katayama Y, Yoshiya K, Shimazu T. Epidemiology and outcome of adult out-of-hospital cardiac arrest of non-cardiac origin in Osaka: a population-based study. BMJ Open 2014; 4: e006462. 
11. Ogawa T, Akahane M, Koike S, Koike S, Tanabe S, Mizoguchi T, Imamura T.

Outcomes of chest compression only CPR versus conventional CPR conducted by lay people in patients with out of hospital cardiopulmonary arrest witnessed by bystanders: nationwide population based observational study. BMJ 2011; 342: c7106.

12. Johnson BV, Coult J, Fahrenbruch C, Blackwood J, Sherman L, Kudenchuk P, Sayre M, Rea T. Cardiopulmonary resuscitation duty cycle in out-of-hospital cardiac arrest. Resuscitation 2015; 87: 86-90.

13. Salcido DD, Sundermann ML, Koller AC, Menegazzi JJ. Incidence and outcomes of rearrest following out-oh-hospital cardiac arrest. Resuscitation 2015; 86: 19-24.

14. Capewell S, Maclmtyre K, Stewart S, Chalmers JWT, Boyd J, Finlayson A, Redpath A, Pell JP. Age, sex, and social trends in out-of-hospital cardiac deaths in Scotland 1986-95: a retrospective cohort study. Lancet 2001; 358: 1213-17.

15. Nagata T, Abe T, Noda E, Hasegawa M, Hashizume M, Hagihara A. Factors associated with the clinical outcomes of paediatric out-of-hospital cardiac arrest in Japan. BMJ Open 2014: 4: e003481.

16. Iwami T, Hiraide A, Nakanishi N, Hayashi Y, Nishiuchi T, Yukioka H, Yoshiya I, Sugimoto H. Age and sex analysis of out-of-hospital cardiac arrest in Osaka, Japan. Resuscitation 2003; 57: 145-52.

17. Iwami T, Hiraide A, Nakanichi N, Hayashi Y, Nishiuchi T, Uejima T, Morita H, Shigemoto T, Ikeuchi H, Matsusaka M, Shinya H, Yukioka H, Sugimoto H. Outcome and characteristics of out-of-hospital cardiac arrest according to location of arrest: A report from a large-scale, population-based study in Osaka, Japan. Resuscitation 2006; 69: 221-8.

18. SOS-KANTO study group. Cardiopulmonary resuscitation by bystanders with chest compression only (SOS-KANTO): an observational study. Lancet 2007; 369: 920-6.

19. Smith K, Lijovic M. Increasing bystander participation in resuscitation. Resuscitation 2014; 85: 1640-1.

20. Tanaka Y, Maeda T, Kamikura T, Nishi T, Omi W, Hashimoto M, Sakagami S, Inaba H. Potential association of bystander-patient relationship with bystander response and patient survival in daytime out-of-hospital cardiac arrest. Resuscitation 2015; 86: 74-81.

21. Takahashi K, Takemura S, Hasegawa M, Kanatani Y, Saitoh D, Sakamoto T. Detection of temporal clustering of emergency medical transport cases who are cardiopulmonary arrest patients in Japan during winter using emergency resuscitation 
statistics. (in Japanese). Journal of Japanese Society for Emergency Medicine 2012; 15: $652-61$

22. Cummins TO, Chamberlain DA, Abramson NS, Allen M, Baskett PJ, Becker L, Bossaert L, Delooz HH, Dick WF, Eisenerg MS. Recommended guidelines for uniform reporting of data from out-of-hospital cardiac arrest: The Utstein style: a statement for health professionals from a task force of the American Heart Association, the European Resuscitation Council, the Heart and Stroke Foundation of Canada, and the Australian Resuscitation Council. Circulation 1991: 84: 960-75.

23. Idris AH, Becker LB, Ornato JP, Hedges JR, Bircher NG, Chandra NC, Cummins RO, Dick W, Ebmeyer U, Halperin HR, Hazinski MF, Kerber RE, Kern KB, Safar P, Steen PA, Swindle MM, Tsitlik JE, von Planta I, von Planta M, Wears RL, Weil MH. Utstein-style guidelines for uniform reporting of laboratory CPR research: A statement for healthcare professionals from a task force of the American heart association the American College of Emergency Physicians, the American College of Cardiology, the European Resuscitation Council, the Heart and Stroke Foundation of Canada, the Institute of Critical Care Medicine, the Safar Center for Resuscitation Research, and the Society for Academic Emergency Medicine. Circulation 1996; 94: 2324-36.

24. Ministry of Education Culture, Sports, Science and Technology of Japan/Ministry of Health, Labour and Welfare of Japan. A Guideline for Epidemiology Studies. (in Japanese). http://www.lifescience.mext.go.jp/files/pdf/37_139.pdf (accessed 1 Apr 2015)

25. Japan Meteorological Agency. Japan Meteorological Agency website. (in Japanese) http://www.data.jma.go.jp/obd/stats/etrn/ (accessed 1 Apr 2015)

26. Kulldorff M, Nagarwalla N. Spatial disease clusters: detection and inference. Statistics in Medicine 1995; 14: 799-810.

27. Armstrong B. Models for the relationship between ambient temperature and daily mortality. Epidemiology 2006; 17(6): 624-31.

DOI: 10.1097/01.ede.0000239732.50999.8f

28. Tango T, Takahashi K. A flexible spatial scan statistic with a restricted likelihood ratio for detecting disease clusters. Statistics in Medicine 2012; 31: 4207-18. DOI: $10.1002 / \operatorname{sim} .5478$

29. R Core Team. R: A Language and Environment for Statistical Computing. R Foundation for Statistical Computing 2014. http://www.R-project.org. (accessed 1 Apr. 2015) 
30. Takahashi K, Yokoyama T, Tango T. FleXScan: Software for the Flexible Scan Statistic. 2013. https://sites.google.com/site/flexscansoftware/ (accessed 1 Apr. 2015) 31. Akaike H. A new look as the statistical model identification. IEEE Transaction on Automatic Control 1974; 19: 716-23.

32. Omori T, Fujimoto G, Yoshimura I, Nitta H, Ono M. Effects of particulate matter on daily mortality in 13 Japanese cities. Journal of Epidemiology 2003; 13(6): 314-22. 33. McMichael AJ, Wilkinson P, Kovats RS, Pattenden S, Hajat S, Armstrong B, Vajanapoom N, Niciu EM, Mahomed H, Kingkeow C, Kosnik M, O’Neill MS, Romieu I, Ramirez-Aguilar M, Barreto ML, Gouveia N, Nikiforov B. International study of temperature, heat and urban mortality: the 'ISOTHURM' project. International Journal of Epidemiology 2008; 37: 1121-31.

34. Ng CFS, Ueda K, Takeuchi A, Nitta H, Konishi S, Bagrowicz R, Watanabe C, Takami A. Sociogeographic variation in the effects of heat and cold on daily mortality in Japan. Journal of Epidemiology 2014; 24(1): 15-24.

35. Fothergill R, Brace-McDonnell GD. Variation in epidemiology and outcomes from cardiac arrest. Resuscitation 2014; 85: 1610-1.

36. Perkins GD, Jacobs IG, Nadkarni VM, Berg RA, Bhanji F, Biarent D, Bossaert LL, Brett SJ, Chamberlain D, de Caen AR, Deakin CD, Finn JC, Gräsner JT, Hazinski MF, Iwami T, Koster RW, Lim SH, Ma MH, McNally BF, Morley PT, Morrison LJ, Monsieurs KG, Montgomery W, Nichol G, Okada K, Ong ME, Travers AH, Nolan JP; for the Utstein Collaborators; for the Utstein Collaborators. Cardiac arrest and cardiopulmonary resuscitation outcome reports: Update of the Utstein resuscitation registry templates for out-of-hospital cardiac arrest. A statement for Healthcare Professionals From a Task Force of the International Liaison Committee on Resuscitation (American Heart Association, European Resuscitation Council, Australian and New Zealand Council on Resuscitation, Heart and Stroke Foundation of Canada, InterAmerican Heart Foundation, Resuscitation Council of Southern Africa, Resuscitation Council of Asia); and the American Heart Association Emergency Cardiovascular Care Committee and the Council on Cardiopulmonary, Critical Care, Perioperative and Resuscitation. Resuscitation 2014. (Epub ahead of print) doi: 10.1016/j.resuscitation.2014.11.002 
Figure 1. Daily out-of-hospital cardiac arrest cases in Japan from 1 January 2005 to 10 March 2011. The orange line shows expected counts derived under Model 1

Male: Cardiac (MC)

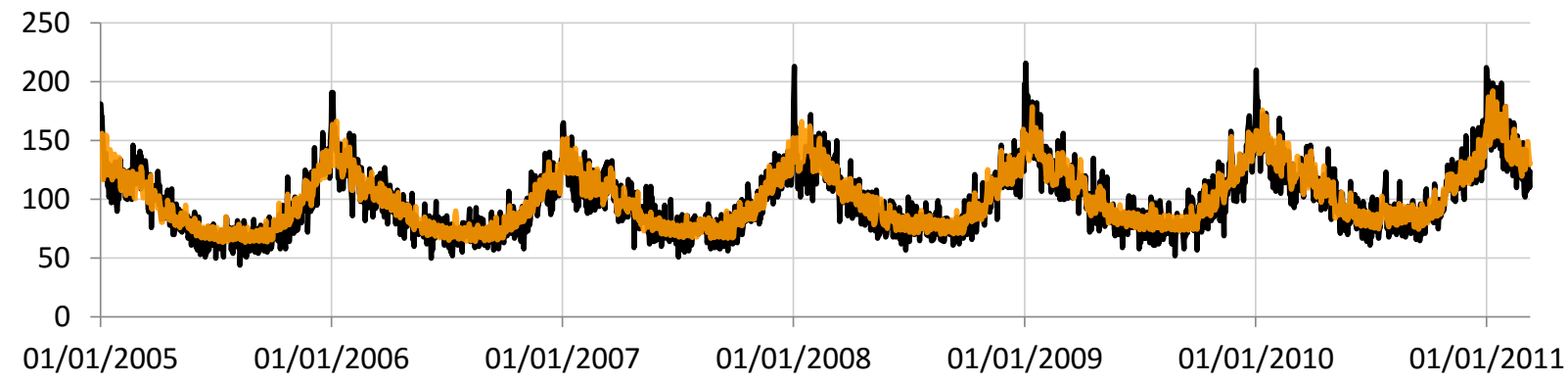

Male: Non-cardiac (MNC)

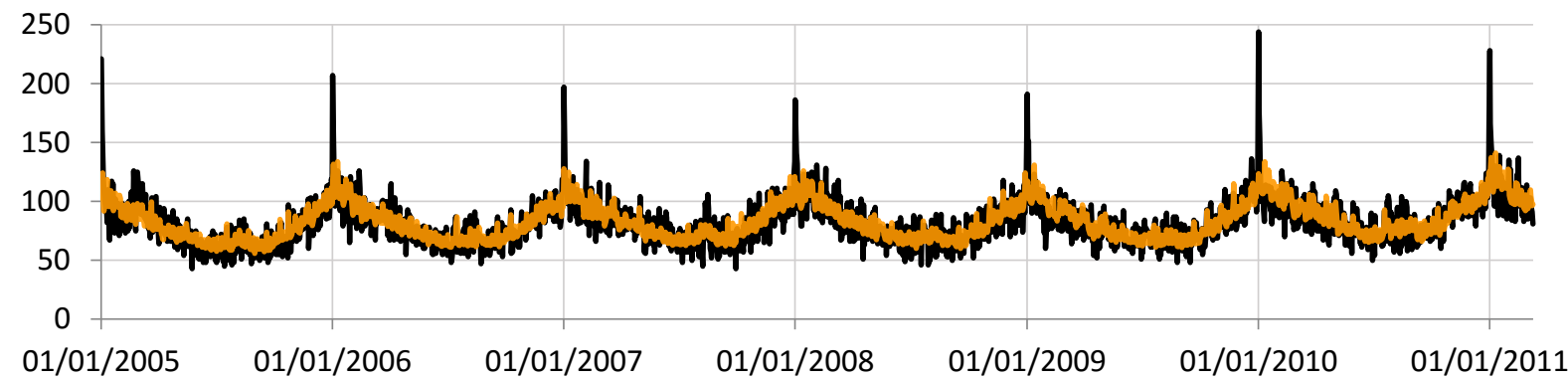

Female: Cardiac (FC)

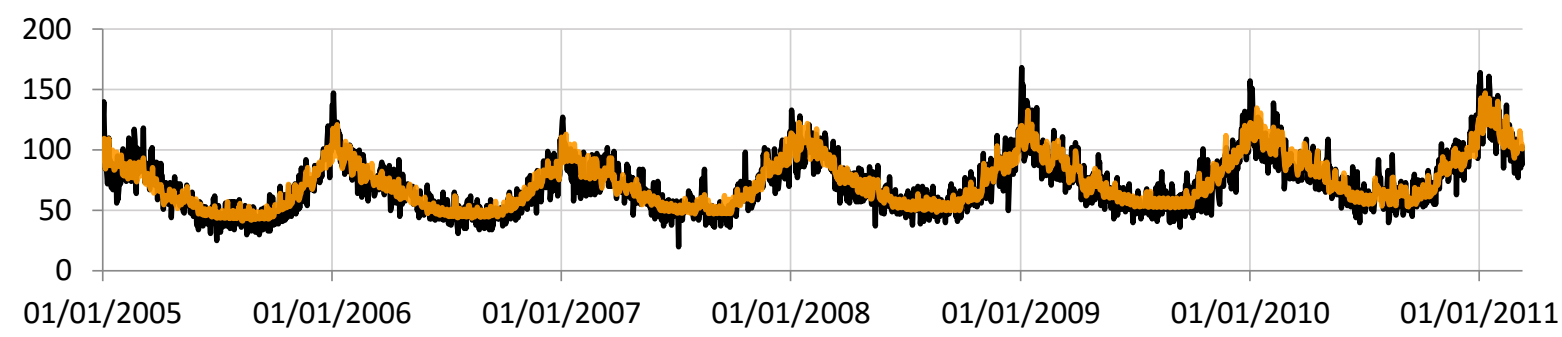

Female: Non-cardiac (FNC)

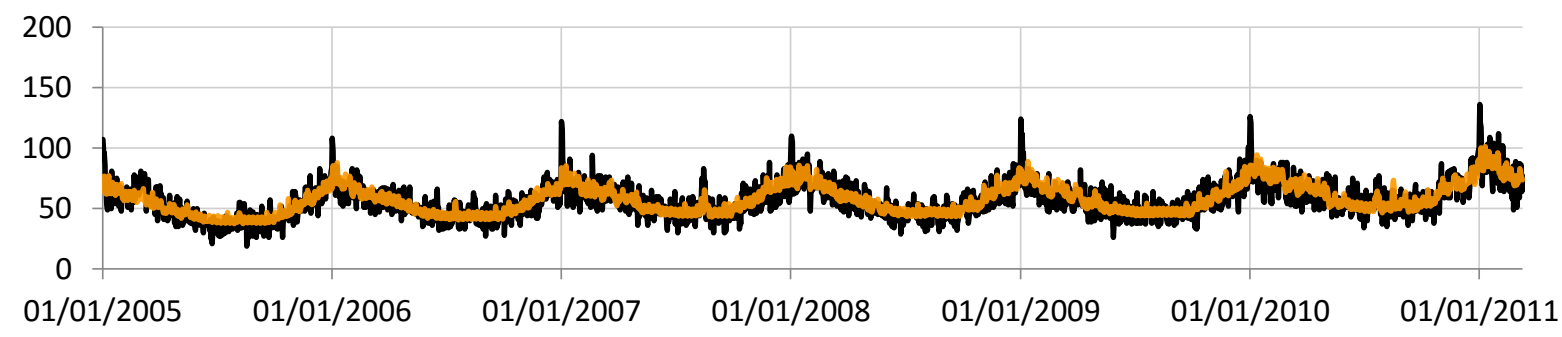


Table 1. Characteristics of patients with out-of-hospital cardiac arrest in Japan, 2005-2011

\begin{tabular}{rrrrr}
\hline & \multicolumn{2}{c}{ Male } & \multicolumn{2}{c}{ Female } \\
\hline \multicolumn{1}{l}{ Total number of cases } & \multicolumn{2}{c}{410,480} & \multicolumn{2}{c}{291,171} \\
\hline Aetiology of OHCA: & Cardiac & Non-cardiac & Cardiac & Non-cardiac \\
\cline { 2 - 6 } Total & 224,661 & 185,819 & 162,680 & 128,491 \\
2005 & 33,280 & 28,095 & 23,132 & 18,231 \\
2006 & 33,606 & 29,302 & 23,576 & 19,458 \\
2007 & 34,288 & 29,798 & 24,713 & 20,662 \\
2008 & 36,724 & 29,714 & 26,572 & 20,817 \\
2009 & 37,518 & 29,534 & 27,441 & 20,757 \\
2010 & 39,003 & 31,865 & 29,290 & 22,937 \\
2011(before March 11) & 10,242 & 7,511 & 7,956 & 5,629 \\
\hline Maximum of daily counts & 216 & 244 & 168 & 136 \\
Minimum of daily counts & 44 & 43 & 20 & 19 \\
\hline
\end{tabular}

OHCA, out-of-hospital cardiac arrest 
Table 2. Detected significant temporal clusters with a significance level of $\alpha=0.05$. Male: Cardiac (MC)

\begin{tabular}{rccccc}
\hline Rank & clustered period & cases & expects & RR & p-value \\
\hline$* 1$ & $2008 / 12 / 31-2009 / 01 / 07$ & 1,458 & $1,165.79$ & 1.25 & 0.001 \\
$* 2$ & $2005 / 12 / 31-2006 / 01 / 07$ & 1,339 & $1,123.91$ & 1.19 & 0.001 \\
$* 3$ & $2010 / 12 / 31-2011 / 01 / 05$ & 1,167 & 969.17 & 1.20 & 0.001 \\
$* 4$ & $2009 / 12 / 31-2010 / 01 / 05$ & 1,094 & 906.31 & 1.21 & 0.001 \\
$* 5$ & $2005 / 01 / 01-2005 / 01 / 05$ & 817 & 666.17 & 1.23 & 0.001 \\
$* 6$ & $2008 / 01 / 01-2008 / 01 / 04$ & 717 & 577.04 & 1.24 & 0.001 \\
7 & $2010 / 05 / 05-2010 / 05 / 07$ & 344 & 265.75 & 1.29 & 0.011 \\
8 & $2005 / 03 / 09-2005 / 03 / 13$ & 627 & 521.62 & 1.20 & 0.028 \\
9 & $2005 / 03 / 29-2005 / 04 / 02$ & 572 & 473.93 & 1.21 & 0.045 \\
\hline
\end{tabular}

Male: Non-cardiac (MNC)

\begin{tabular}{rlcccc}
\hline Rank & clustered period & cases & expects & RR & p-value \\
\hline$* 1$ & $2010 / 01 / 01-2010 / 01 / 02$ & 423 & 232.43 & 1.82 & 0.001 \\
$* 2$ & $2005 / 01 / 01-2005 / 01 / 02$ & 381 & 211.61 & 1.80 & 0.001 \\
$* 3$ & $2011 / 01 / 01$ & 228 & 111.40 & 2.05 & 0.001 \\
$* 4$ & $2008 / 12 / 31-2009 / 01 / 03$ & 630 & 444.54 & 1.42 & 0.001 \\
$* 5$ & $2006 / 01 / 01$ & 207 & 115.10 & 1.80 & 0.001 \\
$* 6$ & $2008 / 01 / 01-2008 / 01 / 04$ & 614 & 446.72 & 1.37 & 0.001 \\
$* 7$ & $2007 / 01 / 01-2007 / 01 / 02$ & 344 & 244.83 & 1.41 & 0.001 \\
$* 8$ & $2011 / 01 / 02-2011 / 01 / 06$ & 711 & 589.98 & 1.21 & 0.008 \\
9 & $2010 / 07 / 22-2010 / 07 / 27$ & 574 & 475.59 & 1.21 & 0.036 \\
\hline
\end{tabular}


Female: Cardiac (FC)

\begin{tabular}{rccccc}
\hline Rank & clustered period & cases & expects & RR & p-value \\
\hline$* 1$ & $2009 / 01 / 02-2009 / 01 / 05$ & 591 & 446.44 & 1.32 & 0.001 \\
$* 2$ & $2005 / 12 / 31-2006 / 01 / 06$ & 885 & 713.74 & 1.24 & 0.001 \\
$* 3$ & $2010 / 01 / 01-2010 / 01 / 05$ & 717 & 579.34 & 1.24 & 0.001 \\
4 & $2010 / 05 / 04-2010 / 05 / 07$ & 382 & 290.36 & 1.32 & 0.002 \\
$* 5$ & $2010 / 12 / 31-2011 / 01 / 02$ & 472 & 373.70 & 1.26 & 0.004 \\
$* 6$ & $2005 / 01 / 01-2005 / 01 / 02$ & 262 & 194.43 & 1.35 & 0.012 \\
7 & $2010 / 07 / 24-2010 / 07 / 27$ & 327 & 254.44 & 1.29 & 0.045 \\
\hline
\end{tabular}

Female: Non-cardiac (FNC)

\begin{tabular}{rccccc}
\hline Rank & clustered period & cases & expects & RR & p-value \\
\hline$* 1$ & $2009 / 12 / 31-2010 / 01 / 02$ & 353 & 244.89 & 1.44 & 0.001 \\
$* 2$ & $2009 / 01 / 01-2009 / 01 / 05$ & 518 & 388.70 & 1.33 & 0.001 \\
$* 3$ & $2011 / 01 / 01-2011 / 01 / 04$ & 477 & 356.09 & 1.34 & 0.001 \\
$* 4$ & $2005 / 01 / 01-2005 / 01 / 04$ & 384 & 279.49 & 1.37 & 0.001 \\
$* 5$ & $2006 / 12 / 31-2007 / 01 / 04$ & 493 & 384.74 & 1.28 & 0.003 \\
$* 6$ & $2008 / 01 / 01-2008 / 01 / 03$ & 323 & 242.22 & 1.33 & 0.004 \\
7 & $2007 / 08 / 09-2007 / 08 / 17$ & 480 & 384.55 & 1.25 & 0.011 \\
8 & $2005 / 08 / 12-2005 / 08 / 15$ & 274 & 204.41 & 1.34 & 0.011 \\
9 & $2005 / 02 / 22-2005 / 02 / 26$ & 362 & 283.58 & 1.27 & 0.034 \\
\hline
\end{tabular}

* shows significantly clustered period around New Year's Day (SCP-NY).

RR: adjusted risk ratio for the clustered period. 
Table 3. Estimated adjusted risk ratio and its p-value in Model 2

\begin{tabular}{|c|c|c|c|c|c|c|c|c|}
\hline \multirow[b]{4}{*}{ variable } & \multirow{3}{*}{\multicolumn{2}{|c|}{$\begin{array}{c}\text { Male } \\
\text { Cardiac } \\
\text { (MC) }\end{array}$}} & \multirow{3}{*}{\multicolumn{6}{|c|}{$\begin{array}{l}\text { Female } \\
\text { Cardiac } \\
\text { (FC) }\end{array}$}} \\
\hline & & & & & & & & \\
\hline & & & & & & & & \\
\hline & $\mathrm{RR}$ & p-value & $\mathrm{RR}$ & p-value & RR & p-value & $\mathrm{RR}$ & p-value \\
\hline constant & - & & - & & - & & & \\
\hline \multicolumn{9}{|l|}{ Year $(\mathrm{ref}=2005)$} \\
\hline 2006 & 1.023 & 0.003 & 1.058 & $<0.001$ & 1.032 & $<0.001$ & 1.086 & $<0.001$ \\
\hline 2007 & 1.064 & $<0.001$ & 1.082 & $<0.001$ & 1.104 & $<0.001$ & 1.157 & $<0.001$ \\
\hline 2008 & 1.116 & $<0.001$ & 1.058 & $<0.001$ & 1.166 & $<0.001$ & 1.153 & $<0.001$ \\
\hline 2009 & 1.155 & $<0.001$ & 1.072 & $<0.001$ & 1.221 & $<0.001$ & 1.162 & $<0.001$ \\
\hline 2010 & 1.179 & $<0.001$ & 1.136 & $<0.001$ & 1.268 & $<0.001$ & 1.265 & $<0.001$ \\
\hline 2011 & 1.241 & $<0.001$ & 1.117 & $<0.001$ & 1.353 & $<0.001$ & 1.305 & $<0.001$ \\
\hline \multicolumn{9}{|l|}{ Month (ref=Jan) } \\
\hline Feb & 0.928 & $<0.001$ & 0.950 & $<0.001$ & 0.931 & $<0.001$ & 0.954 & $<0.001$ \\
\hline Mar & 0.934 & $<0.001$ & 0.940 & $<0.001$ & 0.922 & $<0.001$ & 0.958 & 0.002 \\
\hline Apr & 0.919 & $<0.001$ & 0.934 & $<0.001$ & 0.913 & $<0.001$ & 0.977 & 0.207 \\
\hline May & 0.918 & $<0.001$ & 0.966 & 0.101 & 0.962 & 0.083 & 0.987 & 0.603 \\
\hline Jun & 0.895 & $<0.001$ & 0.950 & 0.041 & 0.897 & $<0.001$ & 0.979 & 0.471 \\
\hline Jul & 0.873 & $<0.001$ & 0.964 & 0.197 & 0.872 & $<0.001$ & 0.966 & 0.274 \\
\hline Aug & 0.862 & $<0.001$ & 0.965 & 0.226 & 0.867 & $<0.001$ & 0.973 & 0.383 \\
\hline Sep & 0.870 & $<0.001$ & 0.963 & 0.169 & 0.867 & $<0.001$ & 0.969 & 0.307 \\
\hline Oct & 0.963 & 0.061 & 1.003 & 0.890 & 0.944 & 0.015 & 1.032 & 0.243 \\
\hline Nov & 1.007 & 0.615 & 1.028 & 0.068 & 1.003 & 0.831 & 1.057 & 0.003 \\
\hline Dec & 1.034 & 0.001 & 1.038 & $<0.001$ & 1.012 & 0.294 & 1.054 & $<0.001$ \\
\hline \multicolumn{9}{|c|}{ Weekday (ref=Sunday) } \\
\hline Mon & 0.970 & $<0.001$ & 0.981 & 0.027 & 0.948 & $<0.001$ & 0.953 & $<0.001$ \\
\hline Tue & 0.891 & $<0.001$ & 0.908 & $<0.001$ & 0.897 & $<0.001$ & 0.903 & $<0.001$ \\
\hline Wed & 0.866 & $<0.001$ & 0.897 & $<0.001$ & 0.888 & $<0.001$ & 0.906 & $<0.001$ \\
\hline Thu & 0.876 & $<0.001$ & 0.885 & $<0.001$ & 0.887 & $<0.001$ & 0.901 & $<0.001$ \\
\hline Fri & 0.881 & $<0.001$ & 0.899 & $<0.001$ & 0.888 & $<0.001$ & 0.887 & $<0.001$ \\
\hline Sat & 0.910 & $<0.001$ & 0.909 & $<0.001$ & 0.909 & $<0.001$ & 0.916 & $<0.001$ \\
\hline Holidays (ref=non) & 1.105 & $<0.001$ & 1.094 & $<0.001$ & 1.153 & $<0.001$ & 1.097 & $<0.001$ \\
\hline
\end{tabular}


Temperature (per $\left.1^{\circ} \mathrm{C}\right)$

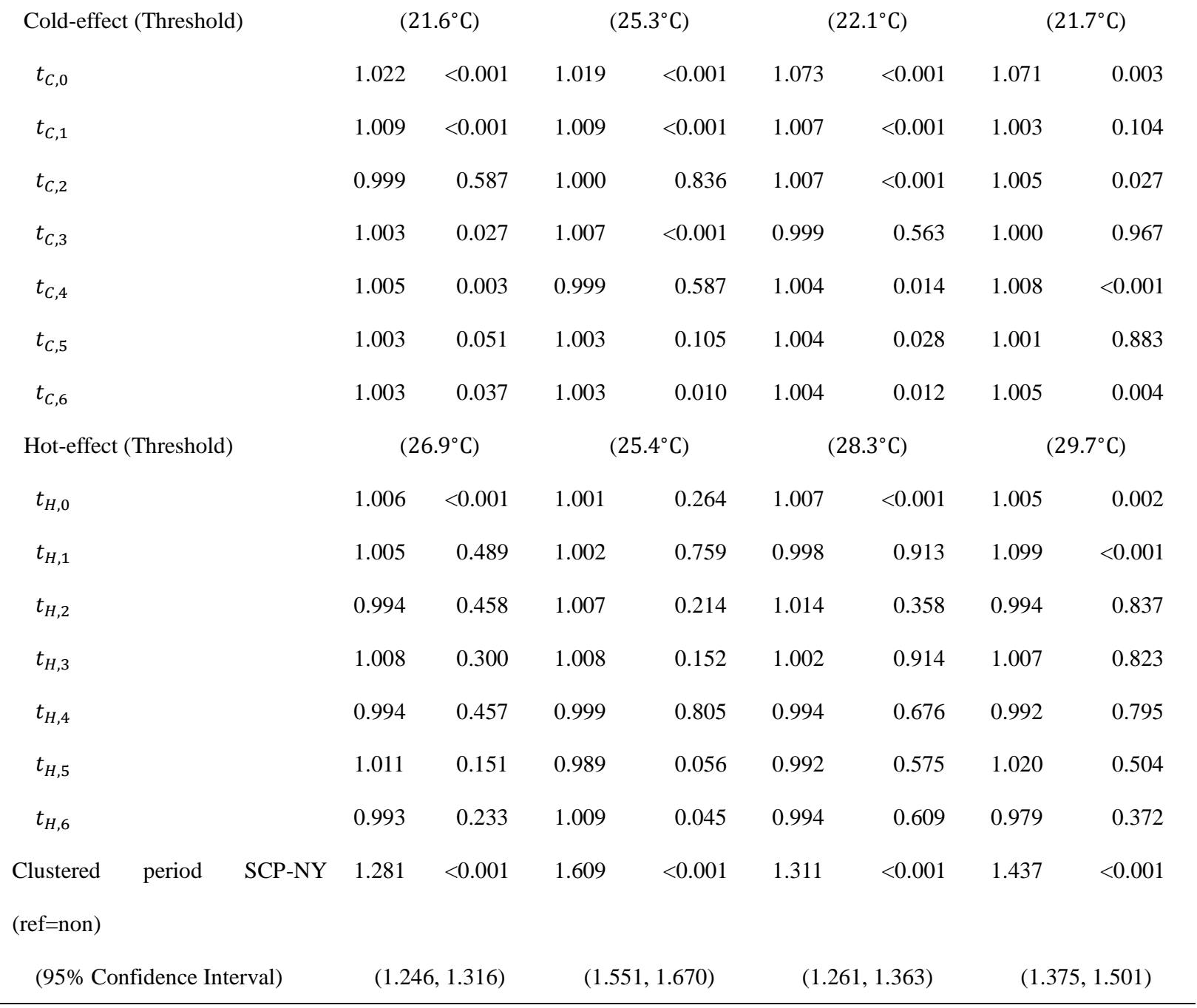

RR, adjusted risk ratio; SCP-NY, significantly clustered period around New Year's Day 